\title{
Nicosulfuron Degradation by an Ascomycete Fungus Isolated From Submerged Alnus Leaf Litter
}

\author{
Louis Carles ${ }^{1}$, Florent Rossi ${ }^{1}$, Pascale Besse-Hoggan ${ }^{2}$, Christelle Blavignac ${ }^{3}$, \\ Martin Leremboure ${ }^{2}$, Joan Artigas ${ }^{1+}$ and Isabelle Batisson ${ }^{1 * \dagger}$
}

' Laboratoire Microorganismes: Génome et Environnement, CNRS, Université Clermont Auvergne, Clermont-Ferrand, France, ${ }^{2}$ Institut de Chimie de Clermont-Ferrand, CNRS, Sigma Clermont, Université Clermont Auvergne, Clermont-Ferrand, France, ${ }^{3}$ Centre Imagerie Cellulaire Santé, Université Clermont Auvergne (UCA PARTNER), Clermont-Ferrand, France

\section{OPEN ACCESS}

Edited by:

Jean-Francois Ghiglione, Centre National de la Recherche

Scientifique (CNRS), France

Reviewed by:

Leif Abrell,

University of Arizona, United States

Huzefa A. Raja,

University of North Carolina

at Greensboro, United States

*Correspondence:

Isabelle Batisson

isabelle.batisson@uca.fr

tThese authors have contributed equally to this work

Specialty section:

This article was submitted to Microbiotechnology, Ecotoxicology and Bioremediation,

a section of the journal

Frontiers in Microbiology

Received: 23 July 2018 Accepted: 07 December 2018 Published: 19 December 2018

Citation:

Carles L, Rossi F,

Besse-Hoggan P, Blavignac C, Leremboure $M$, Artigas $J$ and

Batisson I (2018) Nicosulfuron Degradation by an Ascomycete Fungus Isolated From Submerged Alnus Leaf Litter.

Front. Microbiol. 9:3167. doi: 10.3389/fmicb.2018.03167
Nicosulfuron is a selective herbicide belonging to the sulfonylurea family, commonly applied on maize crops. Its worldwide use results in widespread presence as a contaminant in surface streams and ground-waters. In this study, we isolated, for the first time, the Plectosphaerella cucumerina AR1 nicosulfuron-degrading fungal strain, a new record from Alnus leaf litter submerged in freshwater. The degradation of nicosulfuron by P. cucumerina AR1 was achieved by a co-metabolism process and followed a first-order model dissipation. Biodegradation kinetics analysis indicated that, in planktonic lifestyle, nicosulfuron degradation by this strain was glucose concentration dependent, with a maximum specific degradation rate of $1 \mathrm{~g} / \mathrm{L}$ in glucose. When grown on natural substrata (leaf or wood) as the sole carbon sources, the Plectosphaerella cucumerina AR1 developed as a well-established biofilm in 10 days. After addition of nicosulfuron in the medium, the biofilms became thicker, with rising mycelium, after 10 days for leaves and 21 days for wood. Similar biofilm development was observed in the absence of herbicide. These fungal biofilms still conserve the nicosulfuron degradation capacity, using the same pathway as that observed with planktonic lifestyle as evidenced by LC-MS analyses. This pathway involved first the hydrolysis of the nicosulfuron sulfonylurea bridge, leading to the production of two major metabolites: 2-amino-4,6-dimethoxypyrimidine (ADMP) and 2-(aminosulfonyl)$\mathrm{N}, \mathrm{N}$-dimethyl-3-pyridinecarboxamide (ASDM). One minor metabolite, identified as 2(1-(4,6-dimethoxy-pyrimidin-2-yl)-ureido)-N,N-dimethyl-nicotinamide (N3), derived from the cleavage of the $\mathrm{C}$-S bond of the sulfonylurea bridge and contraction by elimination of sulfur dioxide. A last metabolite (N4), detected in trace amount, was assigned to 2-(4,6dimethoxy-pyrimidin-2-yl)- $N, N$-dimethyl-nicotinamide (N4), resulting from the hydrolysis of the N3 urea function. Although fungal growth was unaffected by nicosulfuron, its laccase activity was significantly impaired regardless of lifestyle. Leaf and wood surfaces being good substrata for biofilm development in rivers, $P$. cucumerina AR1 strain could thus have potential as an efficient candidate for the development of methods aiming to reduce contamination by nicosulfuron in aquatic environments.

Keywords: ascomycete fungus, herbicide, sulfonylurea, degradation, co-metabolism, natural substrata, Plectosphaerella cucumerina 


\section{INTRODUCTION}

Nicosulfuron (2-[(4,6-dimethoxypyrimidin-2-yl)carbamoylsulfamoyl]- $\mathrm{N}, \mathrm{N}$-dimethylpyridine-3-carboxamide) is a sulfonylurea class herbicide used worldwide as a post-emergence herbicide to protect maize crops from weeds. It inhibits acetolactate synthase (ALS) enzyme activity, a key enzyme involved in the branchedchain amino acid biosynthesis (Schloss, 1990), which results in the inhibition of plant growth. Despite the low agronomic dose recommended for nicosulfuron in crops (in Europe, $60 \mathrm{~g}$ active ingredient/ha; CE 1107/2009), this molecule is frequently detected in surface and ground-waters due to its high mobility, its Groundwater Ubiquity Score (GUS) being of 3.34 (Pfeiffer, 2010). This transfer can be explained by the high solubility $(>7 \mathrm{~g} / \mathrm{L}$ at $\mathrm{pH} \geq 6.5$ ) and low $\mathrm{K}_{\mathrm{d}}$ coefficient of the molecule (ranging from 0.14 to $2.15 \mathrm{~L} / \mathrm{kg}$, Gonzalez and Ukrainczyk, 1996, 1999; Oliveira et al., 2001; Regitano and Koskinen, 2008; Trigo et al., 2014; Azcarate et al., 2015). The nicosulfuron environmental concentrations found in various surface waters from Canada, United States, and Europe, averaging $0.3-0.5 \mu \mathrm{g} / \mathrm{L}$, are nonnegligible (Battaglin et al., 2000; de Lafontaine et al., 2014; Moschet et al., 2014), the highest amounts detected peaking up to $3.29 \mu \mathrm{g} / \mathrm{L}$ (Battaglin et al., 2009). Overall, the high detection frequency of nicosulfuron in surface waters implies chronic exposure of aquatic microbial communities and eventually a set of adaptations regarding its use by microbes.

Responses of aquatic fungi to organic contaminants are sequential regarding exposure time and can take from hours to weeks. After an acute exposure to the pesticide, the first fungal responses consist in the oxidative attack of the molecule both in the intracellular (i.e., cytochrome P450 monooxygenases) and/or extracellular (i.e., peroxidases and laccases) spaces, followed by a methylation or conjugation process which improve the molecule solubility as well as its release out of the cell (Krauss et al., 2011). After a chronic exposure, fungi can mineralize the molecule with more or less success.

Regarding the sensitivity of fungi to nicosulfuron, most studies have been performed in soils. For instance, soil fungi are sensitive to nicosulfuron when repeatedly applied at dose rates higher than the recommended one, probably because ALS genes are also present in numerous fungal species (Karpouzas et al., 2014). In contrast, increasing levels of nicosulfuron exposure have been shown to increase the bacterial abundance and diversity in soil (Petric et al., 2016). This tolerance to nicosulfuron seems to be widespread in soil bacteria, mainly among Firmicutes and Actinobacteria. In aquatic microbial communities, responses to nicosulfuron are rather different comparing to those observed in soils (Carles et al., 2017b). While chronic exposure to nicosulfuron enhances fungal diversity in aquatic microbial communities associated with leaf litter, the diversity of bacteria was severely impaired. At the same line, the pre-exposure history of these aquatic microbial communities to contamination played a significant role in their ability to biodegrade nicosulfuron (Carles et al., 2017b).

Degradation of nicosulfuron can require up to 70 days in natural aquatic environments (Cessna et al., 2015), both abiotic and biotic degradation processes co-occurring.
Chemical hydrolysis of the sulfonylurea linkage has been described as the main abiotic degradation process (Sarmah and Sabadie, 2002), its rate being greater as $\mathrm{pH}$ of the medium decreases (Berger and Wolfe, 1996). This phenomenon was also observed for Penicillium oxalicum YC-WM1 where nicosulfuron degradation was due to medium acidification resulting from oxalate secretion by the fungal strain (Feng et al., 2017). Two degradation products are usually formed: 2 -amino4,6-dimethoxypyrimidine (ADMP) and 2-(aminosulfonyl)$\mathrm{N}, \mathrm{N}$-dimethyl-3-pyridinecarboxamide (ASDM), the latter being able to cyclize at basic pH (Sarmah and Sabadie, 2002). Besides, five different photo-products have been identified during nicosulfuron photodegradation in aqueous media (Benzi et al., 2011), though the contribution of this process to total abiotic degradation of the molecule seems to be of minor importance (EFSA, 2007). Regarding biotic degradation, nine bacterial [Oceanisphaera psychrotolerans LAM-WHMZC (Zhou et al., 2017), Bacillus subtilis YB1 (Yang et al., 2008; Lu et al., 2012), Ochrobactrum sp. ZWS16 (Zhao et al., 2015b), Rhodopseudomonas sp. J5-2 (Zhang et al., 2011), Alcaligenes faecalis ZWS11 (Zhao et al., 2015a), Klebsiella sp. Y1 (Wang et al., 2016), Serratia marcescens N80 (Zhang et al., 2012), Pseudomonas fluorescens SG-1 (Carles et al., 2017a) and Pseudomonas nitroreducens strain NSA02 (Zhao et al., 2018)], and three fungal [Talaromyces flavus LZM1 (Song et al., 2013), Aspergillus niger YF1 (Yang et al., 2008; Lu et al., 2012) and Penicillium oxalicum YC-WM1 (Feng et al., 2017)] nicosulfuron-degrading strains have been described in the literature. In most cases, the metabolites identified were ADMP and ASDM, suggesting similar degradation pathways. All these strains have been isolated from environments subjected to high anthropogenic pressure (i.e., wastewater treatment plants, agricultural soils), whereas no data are available about degrading ability of strains exposed to nicosulfuron in final ecological receptors such as river ecosystems.

The present study investigates the capacity of a fungal strain of Plectosphaerella cucumerina AR1, isolated from submerged leaves in a forested river, to degrade nicosulfuron. The influence of lifestyle, accessible carbon source use and activity of the strain during the dissipation process of the herbicide was assessed.

\section{MATERIALS AND METHODS}

\section{Chemicals and Media}

Nicosulfuron (Pestanal, purity 99.6\%) and ADMP (2-amino-4,6dimethoxypyrimidine, purity 98.0\%) were purchased from Sigma Aldrich (France), and ASDM (2-(aminosulfonyl)- $N, N$-dimethyl3-pyridinecarboxamide, purity 98\%) from J and $\mathrm{K}$ Scientific (Germany).

Malt extract and Sabouraud chloramphenicol agar media were purchased from Sigma Aldrich (France). Potato dextrose agar (PDA) medium was obtained from Biomérieux (France). Mineral salt medium (MSM) was composed of (/L): $1 \mathrm{~g}\left(\mathrm{NH}_{4}\right)_{2} \mathrm{HPO}_{4}$, $1 \mathrm{~g} \mathrm{KH}_{2} \mathrm{PO}_{4}, 1 \mathrm{~g} \mathrm{KNO}_{3}, 0.2 \mathrm{~g} \mathrm{MgSO}_{4} .7 \mathrm{H}_{2} \mathrm{O}, 0.1 \mathrm{~g} \mathrm{NaCl}, 20 \mathrm{mg}$ $\mathrm{CaCl}_{2}, 5 \mathrm{mg} \mathrm{FeSO}{ }_{4} .7 \mathrm{H}_{2} \mathrm{O}, 1 \mathrm{~mL}$ of a salt stock solution and $1 \mathrm{~mL}$ of a vitamin stock solution. The salt stock solution contained 


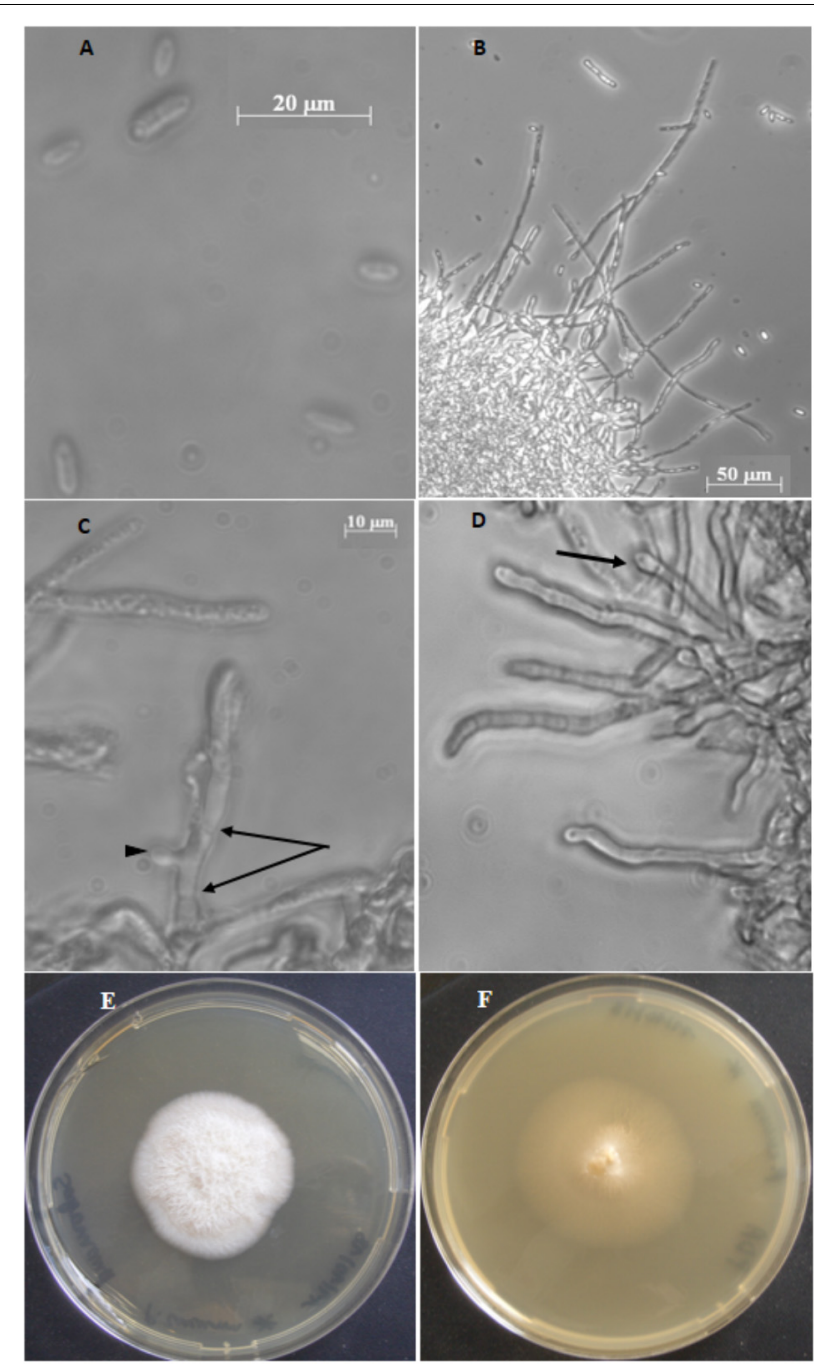

FIGURE 1 | Plectosphaerella cucumerina AR1 strain. (A) Spores. (B) Mycelium with hyphae. (C) Septa hypha (arrows) and budding of hypha (arrow head). (D) Hyphal with phialide (arrow). (E) Colony growth on Sabouraud chloramphenicol agar medium. (F) Colony growth on PDA medium.

(/L) $20 \mathrm{~g}$ boric acid, $18 \mathrm{~g} \mathrm{MnSO}_{4} \cdot \mathrm{H}_{2} \mathrm{O}, 2 \mathrm{~g} \mathrm{ZnSO}, 1 \mathrm{~g} \mathrm{CuSO}$, $2.5 \mathrm{~g} \mathrm{Na}_{2} \mathrm{MoO}_{4}, 10 \mathrm{mg} \mathrm{Co}\left(\mathrm{NO}_{3}\right)_{2}$. The vitamin stock solution contained (/L) $2 \mathrm{mg}$ biotin, $5 \mathrm{mg}$ thiamine- $\mathrm{HCl}$. The glucosemineral salt medium (GSM) was obtained by addition of glucose (10, 5 or $1 \mathrm{~g} / \mathrm{L})$ in MSM. All the media were supplemented by chloramphenicol $(0.5 \mathrm{~g} / \mathrm{L})$.

\section{Isolation and Identification of a Nicosulfuron-Degrading Fungal Strain}

The isolation of fungal species was carried out on a nicosulfurondegrading aquatic microbial community colonizing Alnus glutinosa (L.) Gaertn. leaf species (henceforth referred to Alnus in the text (Carles et al., 2017b)). The isolation was performed according to Artigas et al. (2017). Briefly, sporulation was induced in Alnus communities exhibiting nicosulfuron degradation. Among the spores obtained, a single spore morphotype (fusoid-type; Figure 1A) was physically isolated using glass micropipettes under a microscope (Leica DM IRB, Leica Microsystems, Wetzlar, Germany) and cultivated. Colony morphology was determined on culture grown on PDA or Sabouraud chloramphenicol agar media after 14 days of incubation at $23^{\circ} \mathrm{C}$ in the dark. Mycelium and spores were observed and photographed under an inverted microscope (Ziess, Axiovert 200M). A $10 \mu \mathrm{L}$ spore suspension (containing ca. 15 spores) was then used for germination in $20 \mathrm{~mL}$ of malt extract $1 \%$ ( $\mathrm{pH} 6.5$ ) containing $0.5 \mathrm{mg} / \mathrm{mL}$ of chloramphenicol for 15 days at $28^{\circ} \mathrm{C}$.

The identification of the fungal species was performed through DNA extraction from the fungal mycelium using the Fast DNA SPIN Kit for soil (MP Biomedicals, United States) and following the manufacturer's instructions. Extracted DNA was then amplified by targeting from the fungal $18 \mathrm{~S}$ to the $28 \mathrm{~S}$ regions [using the primer pairs ITS $5\left(5^{\prime}-\right.$ GGAAGTAAAAGTCGTAACAAGC-3') (White et al., 1990) and NL 4 (5'-GGTCCGTGTTTCAAGAC-3') (O’Donnell and Gray, 1995)]. The amplification reaction was carried out in a total volume of $50 \mu \mathrm{L}$ containing $200 \mu \mathrm{M}$ of each deoxyribonucleotide triphosphate (dNTP), $0.2 \mu \mathrm{M}$ of each primer, $1 \mathrm{X}$ PCR buffer containing $2.5 \mathrm{mM} \mathrm{MgCl}_{2}, 0.3 \mathrm{U}$ of Taq polymerase (Eurobio) and $50 \mathrm{ng}$ of genomic DNA. Polymerase chain reactions (PCR) were performed as follows: $5 \mathrm{~min}$ at $95^{\circ} \mathrm{C}$, followed by 35 steps [ $1 \mathrm{~min}$. at $95^{\circ} \mathrm{C}, 2 \mathrm{~min}$. at $52^{\circ} \mathrm{C}$ and $1 \mathrm{~min}$. at $72^{\circ} \mathrm{C}$ ] and a final elongation step at $72^{\circ} \mathrm{C}$ for $7 \mathrm{~min}$. PCR amplicon was then sequenced (MWG - Biotech). The sequence obtained (1118 bp) was compared against NCBI sequences database using BLAST and deposited in GenBank under the Accession No: MK079567.

\section{Biodegradation of Nicosulfuron}

\section{In Planktonic Lifestyle Without or With Glucose as the Carbon Source}

The $100 \mu \mathrm{M}$ nicosulfuron biodegradation capacity of the strain was determined by inoculating from 0.25 to $0.35 \mathrm{mg}$ of mycelium in $100 \mathrm{~mL}$ of mineral medium containing (GSM with 1,5 or $10 \mathrm{~g} / \mathrm{L}$ ) or not (MSM) glucose in $250 \mathrm{~mL}$ flasks. The flasks were incubated at $28^{\circ} \mathrm{C}$ on an orbital shaker at $150 \mathrm{rpm}$ in the dark to avoid photolysis. Noninoculated media served as abiotic controls. Flasks inoculated only with the fungal strain were used as mycelium growth control.

\section{In Biofilm Lifestyle With Leaves or Wood as Carbon Sources}

Alnus leaves and commercial wood-sticks (hazel wood) were macerated overnight in sterile water before being cut in $1 \mathrm{~cm}^{2}$ squares which were used both as supports for fungal biofilm development and as carbon sources for $P$. cucumerina AR1. Squares were then sterilized by autoclaving and added in a $250 \mathrm{~mL}$ flask containing a ten-fold diluted malt medium ( $\mathrm{pH} 6.5), 0.5 \mathrm{~g} / \mathrm{L}$ of chloramphenicol without (control; 48 squares) or with 0.25-0.35 $\mathrm{mg}$ of $P$. cucumerina AR1 mycelium (96 squares). The flasks were incubated at $28^{\circ} \mathrm{C}$ under 
agitation $(80 \mathrm{rpm})$ for 10 days until mature biofilm formation. Then, 16 non-inoculated squares of each substratum were placed into a $250 \mathrm{~mL}$ flask containing $100 \mathrm{~mL}$ of a more environmentally realistic nicosulfuron concentration of $30 \mu \mathrm{M}$ in $\mathrm{Volvic}^{\circledR}$ water (abiotic control). The biofilm-covered squares were incubated in the same way without (growth control) or with $30 \mu \mathrm{M}$ nicosulfuron.

\section{Monitoring of Nicosulfuron Dissipation by P. cucumerina AR1}

Each of the treatments described above for planktonic and biofilm lifestyles was run in triplicate. The time at which nicosulfuron was added to the planktonic or biofilmcovered substrata cultures was considered as Day 0 (D0). The culture media were sampled at days $0,3,6,10,14,21$, 28, and 35 to determine herbicide dissipation by HPLC. The production of metabolites was monitored by LC and LC-(+)ESI-MS. At the end of the experiment (day 35), the fungal pellet (planktonic conditions) or one leaf/wood square (biofilm conditions) was extracted in $0.5 \mathrm{~mL}$ (leaf) and $2.5 \mathrm{~mL}$ (fungal pellet and wood) absolute ethanol to look at sorption onto biomass and/or the substrata. The suspension was stirred vigorously overnight at room temperature and centrifuged $(13,000 \mathrm{~g}$ for $5 \mathrm{~min})$. The extraction was performed twice in order to ensure a complete desorption. The combined organic extracts were concentrated and analyzed by HPLC.

\section{Identification and Quantification of Nicosulfuron and Its Metabolites Monitoring and Quantification by HPLC}

The quantification of nicosulfuron and its main metabolites (ASDM and ADMP), in the culture media (dissipation) and extracted from the fungal biomass, was performed by HPLC on an Agilent Series 1100 chromatograph (Courtaboeuf, France), equipped with a DAD set at $\lambda=220$ and $254 \mathrm{~nm}$, and a reverse phase column (Zorbax Eclipse XDB-C18, $3.5 \mu \mathrm{m}$, $75 \mathrm{~mm} \times 4.6 \mathrm{~mm})$ at $22^{\circ} \mathrm{C}$. The mobile phase was composed of acetonitrile (Solvent A) and acidified water $\left(\mathrm{H}_{3} \mathrm{PO}_{4}, 0.01 \%\right.$

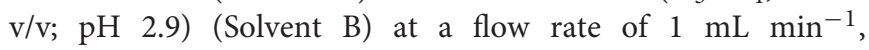
linear gradient $0-1 \mathrm{~min}: 2 \% \mathrm{~A} ; 1-10 \mathrm{~min}: 2-70 \% \mathrm{~A} ; 10-$ 13 min: 70-100\% A; 13 - 13.5 min: 100-2\% A; 13.5 15 min: $0 \%$ A. Injection volume: $5 \mu \mathrm{L}$. Each sample was injected twice. Solutions of the commercially available standards (ASDM and ADMP) were prepared in water, by dilution of a mother solution at $1 \mathrm{mM}$. Each standard solution (covering the expected concentration range) was injected three times. The metabolites $\mathrm{N} 3$ and $\mathrm{N} 4$ can be quantified only by ${ }^{1} \mathrm{H}$ NMR as the standards are not commercially available (Carles et al., 2017a). A "correlation" can be established between the concentrations found by ${ }^{1} \mathrm{H}$ NMR and the HPLC area observed. Nevertheless, this correlation is not very accurate. Therefore the precise concentrations for N3 and $\mathrm{N} 4$ were not given as they remained very low, in particular for N4.

\section{Identification by LC-MS}

LC/ESI-MS analyses were performed on a Thermo Scientific UHPLC Ultimate 3000 RSLC coupled with an Orbitrap Q-Exactive analyzer. The crude supernatants were harvested (5 min at 13,000 $\mathrm{g}$ ) before LC-MS analyses and directly injected in the LC-MS system without any further treatment. The analyses were carried out in positive mode. The UHPLC was equipped with a Kinetex EVO C18; 100 x $2.1 \mathrm{~mm} ; 1.7 \mu \mathrm{m}$ (Phenomenex) at $30^{\circ} \mathrm{C}$ with a gradient acetonitrile $+0.1 \%$ Formic acid (Solvent A) and water $+0.1 \%$ Formic acid (Solvent B): 0-7.5 min: 5-99\% A (linear); 7.5-8.5 min: 99\% A; 8.5-9 min: 99-5\% A; 9-11 min: $5 \%$ A. Flow: $0.45 \mathrm{~mL} / \mathrm{min}$. For the mass spectrometer, gaseous $\mathrm{N}_{2}$ was used as nebulizer gas $(50 \mathrm{~L} / \mathrm{h})$. The spray voltage was $3.2 \mathrm{kV}$. The mass resolution used was 35,000 .

\section{Laccase Activity Measurements}

Laccase (EC 1.10.3.2) activity was measured in triplicate at each sampling date from planktonic (varying from 3 to $8 \mathrm{mg}$ of fungal dry mycelium) and biofilm (one square of leaf/wood) samples using the 2,2'-Azino-bis(3-ethylbenzthiazoline-6-sulfonic acid) (ABTS) substrate (Sigma-Aldrich, St. Louis, MO, United States). Enzyme activity assays were conducted according to the protocol of Johannes and Majcherczyk (2000) with some modifications. Substrate saturating conditions were fixed at $3 \mathrm{mM}$ ABTS and incubations were performed during $1 \mathrm{~h}$ at $20^{\circ} \mathrm{C}$, under agitation $(80 \mathrm{rpm})$ in the dark. ABTS transformation was measured spectrophotometrically $(420 \mathrm{~nm})$ using an Ultrospec 2000 device (Pharmacia Biotech, Trowbridge, United Kingdom). The enzymatic activity was expressed as $1 \mathrm{U}=1 \mu \mathrm{mol}$ ABTS oxidized/g mycelium dry mass $/ \mathrm{h}\left(\varepsilon_{420}=36 \mathrm{M}^{-1} \mathrm{~cm}^{-1}\right.$, Johannes and Majcherczyk, 2000). Oven dry mass (DM) was determined systematically for each sample and used to correct laccase activity (activity/h/g DM).

\section{Biomass Measurements}

In the planktonic conditions, fungal biomass production was determined as the dry mass difference between D0 and D35. Biomass corresponding to laccase activity assays was also determined and added to fungal biomass calculations. The biofilm condition did not allow us to calculate a proper fungal biomass production because of the influence of the substrata which was degraded in parallel along the experiment.

\section{Scanning Electron Microscopy (SEM)}

Leaf or wood supports, exposed to nicosulfuron and P. cucumerina AR1 strain (biofilm) or not (control), were sampled at D0, D10, D21 and D35 and fixed overnight at $4^{\circ} \mathrm{C}$ in $0.2 \mathrm{~mol} / \mathrm{L}$ sodium cacodylate buffer $\mathrm{pH} 7.4$ that contained $1.6 \%$ glutaraldehyde. Biofilms were then washed and post-fixed $1 \mathrm{~h}$ with $1 \%$ osmium tetroxide in $0.2 \mathrm{~mol} / \mathrm{L}$ sodium cacodylate buffer ( $\mathrm{pH}$ 7.4). They were washed $20 \mathrm{~min}$. in distilled water and the dehydration by graded ethanol was performed from $25^{\circ}$ to $100^{\circ}$ (10 min each) to finish in hexamethyldisilazane (HMDS) for $10 \mathrm{~min}$. After drying, the samples were mounted on stubs using adhesive carbon tabs and sputter-coated with gold-palladium (JFC-1300, JEOL, Japan). 
Morphology analysis was carried out using a scanning electron microscope JSM-6060LV (Jeol, Japan) at $5 \mathrm{kV}$ in high-vacuum mode.

\section{Statistical Analyses}

Nicosulfuron dissipation and metabolite production were fitted to an exponential decay model ( $\mathrm{f}=a \times \exp (-b \times \mathrm{x})$ ) with (a) initial nicosulfuron concentration and $(b)$ dissipation rate as parameters estimated) and a sigmoidal model ( $\mathrm{f}=a /(1+\exp (-$ $\left.\left.\left(\mathrm{x}-x_{0}\right) / b\right)\right)$ ) with $a$ (maximal ADMP or ASDM concentration), $b$ (production rate) and $x_{0}$ (time when the maximal production rate was achieved) as estimated parameters), respectively, using Sigma Plot 10.0 for Windows (Systat Software, Inc.). Differences on the nicosulfuron dissipation rate and metabolite production rate between treatments were assessed using a one-way ANOVA test followed by Tukey HSD test. ANOVA tests for the planktonic lifestyle experiments used glucose as the fixed factor (10, 5, or $1 \mathrm{~g} / \mathrm{L})$, whereas in biofilm lifestyle experiment, it was the substratum (leaf, wood). Before ANOVA testing, data were assessed for normality and homoscedasticity. Log transformations were applied when data did not follow ANOVA assumptions.

\section{RESULTS}

\section{Characterization of Plectosphaerella cucumerina AR1}

The fungal spores isolated from submerged Alnus leaf communities were fusiform, ends rounded, measuring 8-13 $\mu \mathrm{m}$ in length and 2.5-4 $\mu \mathrm{m}$ in width (Figure 1A). Based on ITS1-5.8S-ITS2-28S region sequencing and on macro- and microscopic characters, the isolated fungus was identified as Plectosphaerella cucumerina species and named Plectosphaerella cucumerina AR1.

When cultivated in planktonic conditions, the isolated P. cucumerina AR1 strain formed threadlike hyphae that grow into a mycelium forming a cottony mass (Figure 1B). Hyphae are septated and produce bud leading to branched mycelium (Figure 1C). Solitary phialides can be produced forming a flask-shaped projection on the apex of the septated hyphae (Figure 1D).

The Plectosphaerella cucumerina AR1 colony showed different aspects depending on the solid culture medium used, varying from a white, fluffy and aerial mycelium in Sabouraud chloramphenicol agar medium (Figure 1E) to a beige, smooth in appearance with some white mycelia diffusing from a central dome in PDA medium (Figure 1F). In both cases, the diameter of the colonies reached around $4.5 \mathrm{~cm}$ after 14 days at $23^{\circ} \mathrm{C}$.

\section{Biodegradation of Nicosulfuron by Planktonic $P$. cucumerina AR1}

$P$. cucumerina AR1 cultivated in mineral medium (MSM) was unable to dissipate $100 \mu \mathrm{M}$ nicosulfuron (data not shown).

Nevertheless, when glucose was added as a carbon source, a dissipation of nicosulfuron was observed that follows an exponential decay model $\left(R^{2}>0.91\right.$ and $P<0.001$ for all the conditions tested). This was not the case in abiotic controls. We thus studied the glucose concentration effect, used as a classic co-metabolic substrate, on nicosulfuron biodegradation (Figure 2). The dissipation rates increased with the glucose concentrations (ANOVA, $P<0.0001$ ) (Tukey's test, $P<0.05$ ) (Table 1). Nicosulfuron $(100 \mu \mathrm{M})$ has completely disappeared after 21 days of incubation for a concentration of $10 \mathrm{~g} / \mathrm{L}$ of glucose, whereas around $1.5 \%$ and $13 \%$ of nicosulfuron were still remaining after 35 days of culture, for concentrations of 5 and $1 \mathrm{~g} / \mathrm{L}$, respectively. Besides, only $2,1.6$, and $1.3 \%$ of nicosulfuron were recovered after extraction of the fungal biomass with ethanol after 35 days, when cultures were carried out with $10 \mathrm{~g} / \mathrm{L}, 5 \mathrm{~g} / \mathrm{L}$ and $1 \mathrm{~g} / \mathrm{L}$ of glucose, respectively (data not shown). Therefore, biosorption was not a significant process in herbicide dissipation. The degradation of nicosulfuron and growth of the fungal strain did not modify the $\mathrm{pH}$ of the culture media which were all measured at $6.50 \pm 0.22(n=18)$ at the end of the experiment.

During the HPLC monitoring of nicosulfuron $\left(t_{\mathrm{R}}=7.6 \mathrm{~min}\right)$ biodegradation, two new peaks appeared at shorter retention times $\left(t_{\mathrm{R}}=4.3\right.$ and $\left.5.2 \mathrm{~min}\right)$ with increasing intensities with time. They were absent from the controls. Analyses of the same samples by LC-(+)ESI-MS gave a molecular ion at $\mathrm{m} / \mathrm{z} 230.0587[\mathrm{M}+\mathrm{H}]^{+}$ $\left(\mathrm{C}_{8} \mathrm{H}_{12} \mathrm{~N}_{3} \mathrm{O}_{3} \mathrm{~S}^{+}\right)$and main fragment ions at $\mathrm{m} / \mathrm{z} 252.0405$ $[\mathrm{M}+\mathrm{Na}]^{+}$and $213.0323\left(\mathrm{C}_{8} \mathrm{H}_{9} \mathrm{~N}_{2} \mathrm{O}_{3} \mathrm{~S}^{+}\right)$for the metabolite with

TABLE 1 | Kinetic parameters of nicosulfuron dissipation and metabolite formation in the presence of various glucose concentrations or natural substrata.

\begin{tabular}{|c|c|c|c|c|c|}
\hline & & $\begin{array}{l}\text { Dissipation (1) } \\
\text { and } \\
\text { production }(2) \\
\text { rates }(/ \mathrm{h})\end{array}$ & SE & $R^{2}$ & $P$-value \\
\hline \multirow[t]{11}{*}{ Glucose } & Nicosulfuron & & & & \\
\hline & $\begin{array}{l}\text { Glucose } \\
1 \mathrm{mg} / \mathrm{L}\end{array}$ & $0.0739^{(1) a}$ & 0.0013 & 0.9546 & $<0.0001$ \\
\hline & $\begin{array}{l}\text { Glucose } \\
5 \mathrm{mg} / \mathrm{L}\end{array}$ & $0.1048^{(1) b}$ & 0.0061 & 0.9592 & $<0.0001$ \\
\hline & $\begin{array}{l}\text { Glucose } \\
10 \mathrm{mg} / \mathrm{L}\end{array}$ & $0.1381^{(1) c}$ & 0.0042 & 0.9139 & $<0.001$ \\
\hline & Metabolites & & & & \\
\hline & ADMP (1 mg/L) & $5.3795^{(2) a}$ & 0.5782 & 0.9545 & $<0.001$ \\
\hline & ADMP (5 mg/L) & $4.8287^{(2) a}$ & 0.0518 & 0.9882 & $<0.0001$ \\
\hline & $\begin{array}{l}\text { ADMP } \\
(10 \mathrm{mg} / \mathrm{L})\end{array}$ & $3.9844^{(2) a}$ & 0.0920 & 0.9944 & $<0.0001$ \\
\hline & ASDM (1 mg/L) & $3.1444^{(2) a}$ & 0.0934 & 0.9895 & $<0.0001$ \\
\hline & ASDM (5 mg/L) & $2.9618^{(2) a b}$ & 0.0519 & 0.9923 & $<0.0001$ \\
\hline & $\begin{array}{l}\text { ASDM } \\
(10 \mathrm{mg} / \mathrm{L})\end{array}$ & 2.5519 (2)bc & 0.1298 & 0.9918 & $<0.0001$ \\
\hline \multirow{3}{*}{$\begin{array}{l}\text { Natural } \\
\text { substrata }\end{array}$} & Nicosulfuron & & & & \\
\hline & Leaves & $0.1137^{(1) a}$ & 0.0021 & 0.9512 & $<0.0001$ \\
\hline & Wood & 0.1139 (1)a & 0.0087 & 0.8815 & $<0.001$ \\
\hline
\end{tabular}

Parameters are expressed as the mean standard error (SE), $n=3$. Significant differences between conditions are indicated by letters (Tukey test, $P<0.05$ ). 

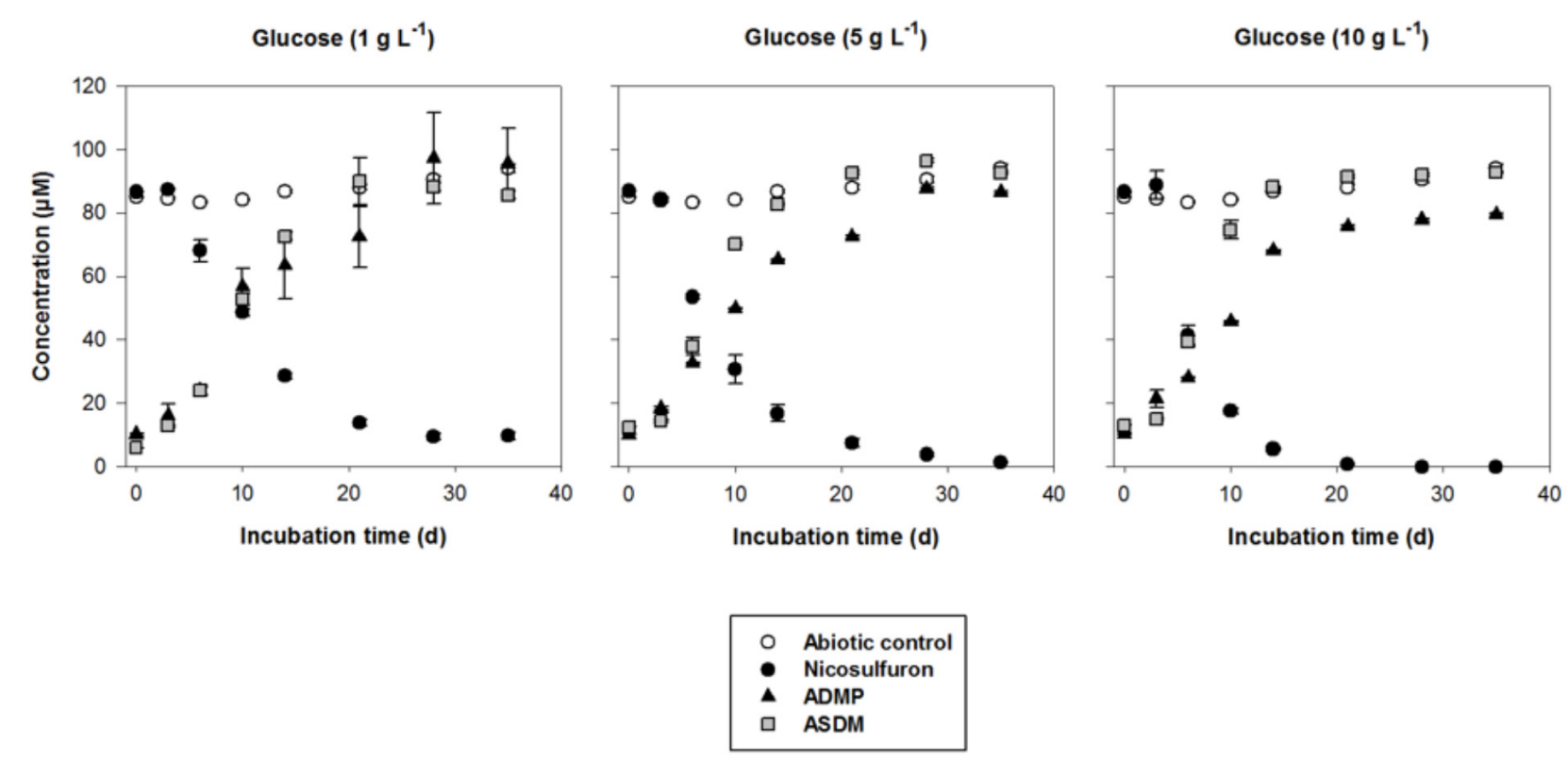

FIGURE 2 | Biodegradation of $100 \mu \mathrm{M}$ nicosulfuron and production of the major metabolites (ADMP and ASDM) by P. cucumerina AR1 strain in planktonic lifestyle in the presence of $1 \mathrm{~g} / \mathrm{L}, 5 \mathrm{~g} / \mathrm{L}$, and $10 \mathrm{~g} / \mathrm{L}$ of glucose. The abiotic controls were non-inoculated with the strain. Values are expressed as the mean \pm standard error (SE), $n=3$.

the shortest retention time and a molecular ion at $\mathrm{m} / \mathrm{z} 156.0766$ $[\mathrm{M}+\mathrm{H}]^{+}\left(\mathrm{C}_{6} \mathrm{H}_{10} \mathrm{~N}_{3} \mathrm{O}_{2}{ }^{+}\right)$for the second metabolite. According to the literature (Zhao et al., 2015a) and to our previous research work (Carles et al., 2017a), they were assigned to ASDM (2-(aminosulfonyl)- $N, N$-dimethyl-3-pyridinecarboxamide) and ADMP (2-amino-4,6-dimethoxypyrimidine), respectively. The structures of both metabolites were confirmed by comparison with the LC-(+)ESI-MS data of the commercially available standard compounds under the same conditions. These two metabolites are formed by the cleavage of the $\mathrm{C}-\mathrm{N}$ bond in the sulfonylurea bridge (Supplementary Figure S1). The ASDM production was faster at $10 \mathrm{~g} / \mathrm{L}$ of glucose compared to $1 \mathrm{~g} / \mathrm{L}$ (Tukey's test, $P<0.05$; Table 1 and Figure 2), accordingly to the results observed with nicosulfuron. Conversely, the production kinetics of ADMP showed no significant difference whatever the glucose concentration tested (Table 1). Nevertheless, both metabolites were present in similar molar concentrations $(\sim 80-$ $90 \mu \mathrm{M})$ after 35 days of incubation (Figure 2). Another metabolite, presenting a molecular ion at $\mathrm{m} / \mathrm{z} 347.1456$ $[\mathrm{M}+\mathrm{H}]^{+}\left(\mathrm{C}_{15} \mathrm{H}_{19} \mathrm{~N}_{6} \mathrm{O}_{4}{ }^{+}\right)$, a retention time at $2.8 \mathrm{~min}$ and a main fragment ion at $\mathrm{m} / \mathrm{z} 304.1396\left(\mathrm{C}_{14} \mathrm{H}_{18} \mathrm{~N}_{5} \mathrm{O}_{3}{ }^{+}\right)$, was also detected by LC-(+)ESI-MS in a low amount. It was identified as 2-(1-(4,6-dimethoxy-pyrimidin-2-yl)-ureido)- $\mathrm{N}, \mathrm{N}$ dimethyl-nicotinamide (N3) (Supplementary Figure S1) (Carles et al., 2017a). Therefore our results indicate that nicosulfuron was mainly co-metabolically degraded by $P$. cucumerina AR1.

The greater the glucose concentration supplied was, the faster the nicosulfuron dissipation (Figure 2 and Table 1). This result can be explained by an increase of mycelium biomass with the increase of glucose concentrations, irrespective of presence of nicosulfuron (ANOVA, $P<0.0001$, Figure 3). However, specific nicosulfuron dissipation calculations (corrected by mycelium biomass) showed an inverse correlation between specific nicosulfuron dissipation and glucose concentration, varying from $19 \%$ at $1 \mathrm{~g} / \mathrm{L}$ glucose to $8 \%$ at $10 \mathrm{~g} / \mathrm{L}$ (Figure 4).

Although nicosulfuron has no impact on $P$. cucumerina AR1 growth, laccase activity was significantly impaired by both the presence of nicosulfuron and the increasing concentration of glucose (ANOVA, $P<0.0001$ for both factors; Figure 5A). Only $30 \%$ of the laccase activity remained when $P$. cucumerina AR1 was jointly exposed to nicosulfuron and $10 \mathrm{~g} / \mathrm{L}$ glucose compared to $1 \mathrm{~g} / \mathrm{L}$ (Tukey's test $P<0.05)$.

\section{Biodegradation of Nicosulfuron by Benthic $P$. cucumerina AR1 Characterization of the Biofilm Development}

The P. cucumerina AR1 capacity to degrade nicosulfuron in benthic conditions was tested on two natural substrata (alder leaf and hazel wood). The biofilm evolution was monitored by SEM analyses. The SEM micrographs showed no microbial development on leaf and wood supports sterilized by autoclave and incubated in $1 / 10$ diluted malt $1 \%$ medium, pH 6.5 (Figures 6A,B control; D0). In contrast, supports inoculated with P. cucumerina AR1 presented a wellestablished biofilm before nicosulfuron addition (Figures 6A,B biofilm; D0).

These biofilms were then exposed to nicosulfuron in Volvic ${ }^{\circledR}$ water. The architecture of biofilms evolved slightly 


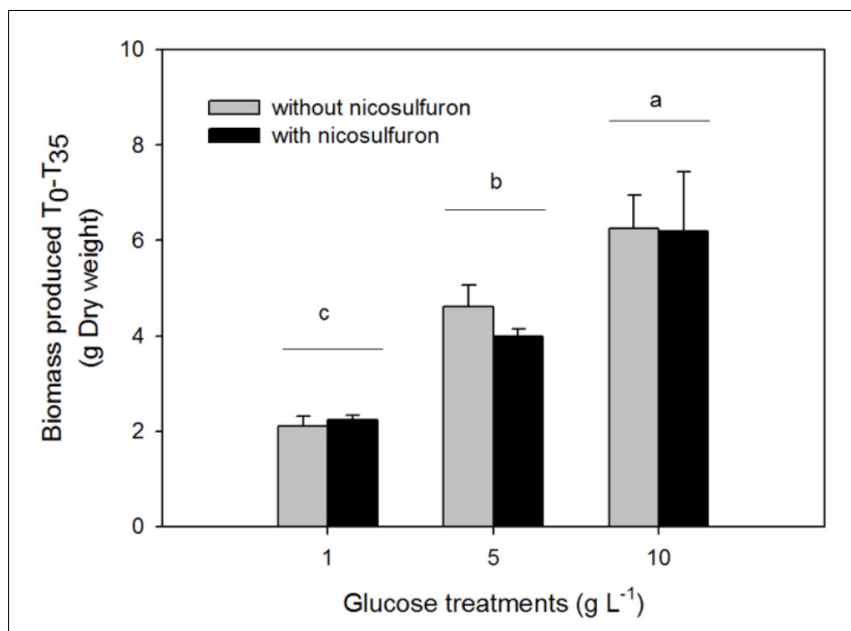

FIGURE 3 | Biomass production of $P$. cucumerina AR1 in the presence of various glucose concentrations and with or without $100 \mu \mathrm{M}$ nicosulfuron after 35-day incubation. Values are expressed as the mean \pm standard error (SE), $n=3$. Differences between experimental conditions are marked by letters $\mathrm{a}>\mathrm{b}>\mathrm{c}$ (Tukey's test, $P<0.05)$.

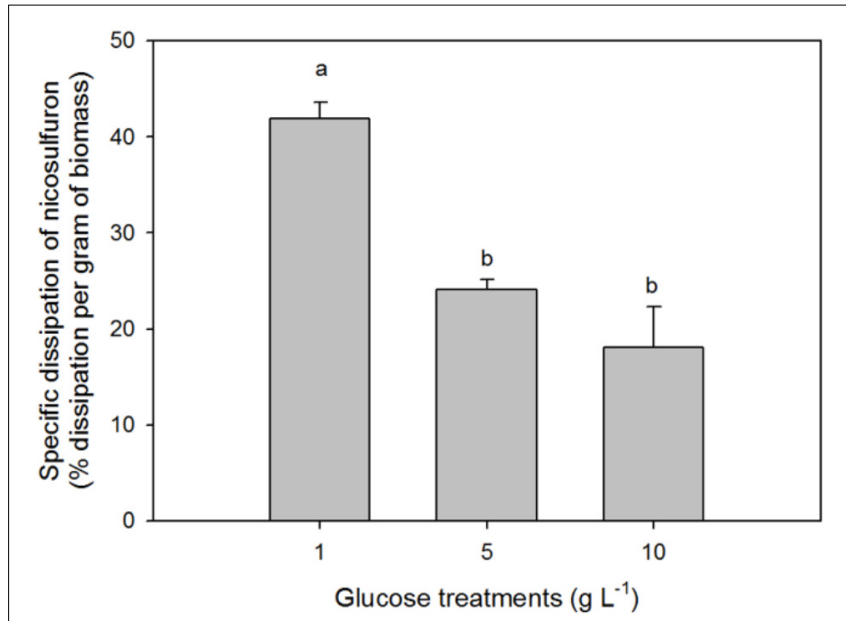

FIGURE 4 | Specific biodegradation percentage of $100 \mu \mathrm{M}$ nicosulfuron by $P$. cucumerina AR1 in the presence of various glucose concentrations. Values are expressed as the mean \pm standard error (SE), $n=3$. Differences between treatments are marked by letters $\mathrm{a}>\mathrm{b}$ (Tukey's test, $P<0.05$ ).

differently between leaf and wood substrata. Specifically, a compact and thick biofilm, with rising mycelium, was formed more rapidly on leaves (10 days; Figure 6A biofilm; D10) than on wood (21 days; Figure 6B biofilm; D21). At the end of the experiment, both biofilm structures were comparable (Figures 6A,B biofilm; D35), without apparent differences between control biofilms and those exposed to nicosulfuron.

\section{Nicosulfuron Biodegradation}

The dissipation of nicosulfuron $(30 \mu \mathrm{M})$ was observed both for leaf and wood grown biofilms (Figure 7). The adsorption of nicosulfuron on subtrata was around $0.15 \pm 0.076 \%$ and $2.82 \pm 0.69 \%(n=3)$ for leaf and wood, respectively (data not shown). Surprisingly, wood grown biofilms were able to degrade nicosulfuron as soon as they were exposed to the herbicide, as opposed to leaf grown biofilms which showed a 3 day delay in nicosulfuron degradation (Figure 7). Nevertheless, the nicosulfuron degradation kinetics was the same overall, exhibiting comparable rates, whatever the substratum tested (Table 1). At day 21, the nicosulfuron degradation by the wood grown biofilms was maximal, reaching around $97 \%$ dissipation. Then, the nicosulfuron concentration remained unchanged until the end of the experiment. On the contrary, for the leaf grown biofilms, the degradation of nicosulfuron reached also $97 \%$ after 21 days and continued up to $100 \%$ at the end of the experiment (Figure 7). During this biodegradation process, the $\mathrm{pH}$ of the medium was not significantly modified since the values were of $6.40 \pm 0.36$ at the end of the experiment under all the conditions.

Nicosulfuron was degraded by biofilms with the same pathway as that observed for planktonic lifestyle. The two major metabolites, ADMP and ASDM as well as the minor one, N3, were formed under these conditions (data not shown). A fourth metabolite, with a retention time of $2.3 \mathrm{~min}$ and a molecular ion at $\mathrm{m} / \mathrm{z} 304.1396[\mathrm{M}+\mathrm{H}]^{+}\left(\mathrm{C}_{14} \mathrm{H}_{18} \mathrm{~N}_{5} \mathrm{O}_{3}{ }^{+}\right)$, was also detected by LC-(+)ESI-MS after 6 days of incubation but in a very low amount. This ion was already observed in the mass spectrum of $\mathrm{N} 3$ as the main fragment ion, suggesting that N4 came directly from N3. It was assigned as 2-(4,6-dimethoxy-pyrimidin2-yl)-N,N-dimethyl-nicotinamide (N4) by comparison with the literature data (Carles et al., 2017a) (Supplementary Figure S1).

During the 35-day experiment, the integrated laccase activity was about 8 times higher for leaf grown biofilms compared to wood grown biofilms (Figure 5B). This activity was decreased (about 55-60\%) when biofilms were exposed to nicosulfuron.

\section{DISCUSSION}

Plectosphaerella cucumerina AR1 is a filamentous Ascomycete fungus, mostly encountered in the terrestrial environment as a pathogen of various plant species and vegetables [e.g., lettuce (Usami and Katagiri, 2017), cabbage (Li et al., 2017), broomrape (Xu et al., 2016), sunflower (Zhang et al., 2015), bottle gourd (Yan et al., 2016), tomato, melon (Carlucci et al., 2012), potato (Gao et al., 2016)] and to a lesser extent in marine ecosystems where it has been described as host of ascidian invertebrates (López-Legentil et al., 2015), sponges (Wang et al., 2008) and shells (Velmurugan et al., 2011). To our knowledge, this is the first time that P. cucumerina (Figure 1) has been isolated from submerged plant litter in a freshwater ecosystem.

Furthermore, $P$. cucumerina AR1 was described as a biological control agent against potato cyst nematodes (Atkins et al., 2003; Jacobs et al., 2003; Dandurand and Knudsen, 2016; Kooliyottil et al., 2017). It was used as a bioherbicide in agricultural crops and pastures (Bailey K. et al., 2017; Bailey K.L. et al., 2017) and would also be involved in the remediation of metal polluted environments (Santelli et al., 2010, 2011). 
A

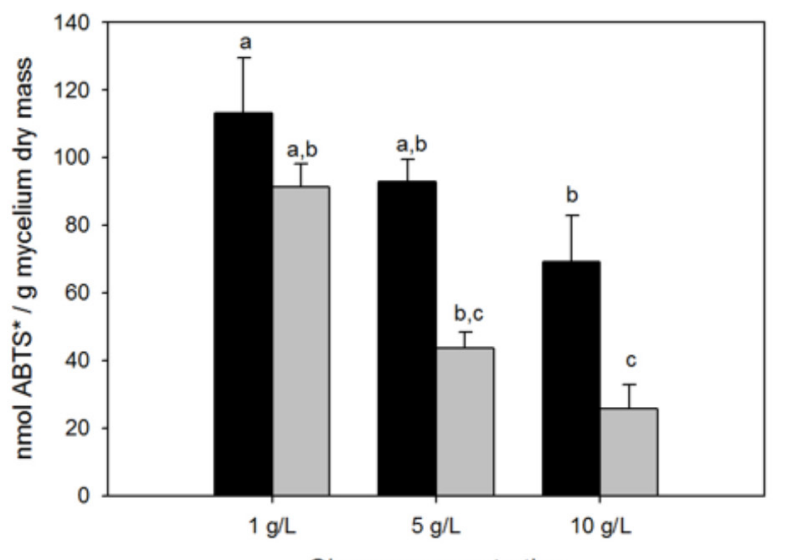

B

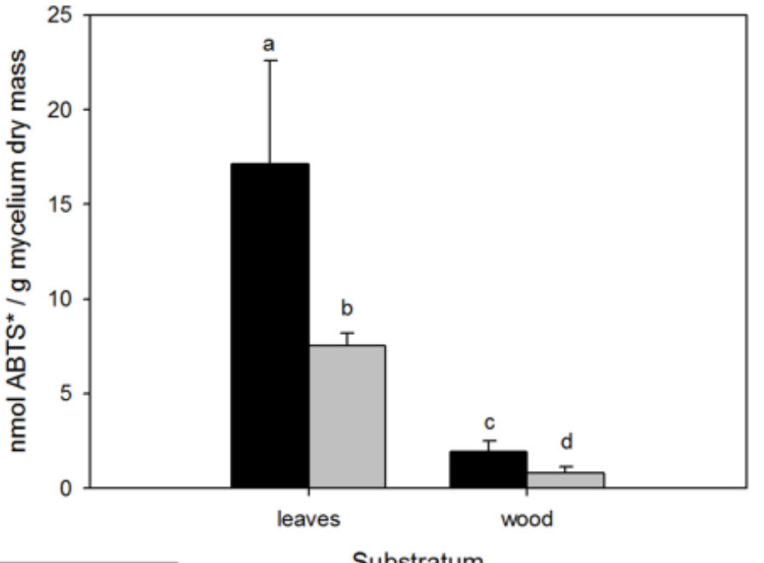

without nicosulfuron with nicosulfuron

FIGURE 5 | (A) Integrated 35-day laccase activity in fungal mycelia grown in the presence or absence of nicosulfuron at different glucose concentrations (1, 5, and $10 \mathrm{~g} / \mathrm{L})$. (B) Integrated 35-day laccase activity in leaf and wood biofilms supplemented or not with nicosulfuron. Values are expressed as the mean \pm standard error (SE), $n=3$. Differences between experimental conditions are marked by letters $a>b>c>d$ (Tukey's test, $P<0.05$ ).

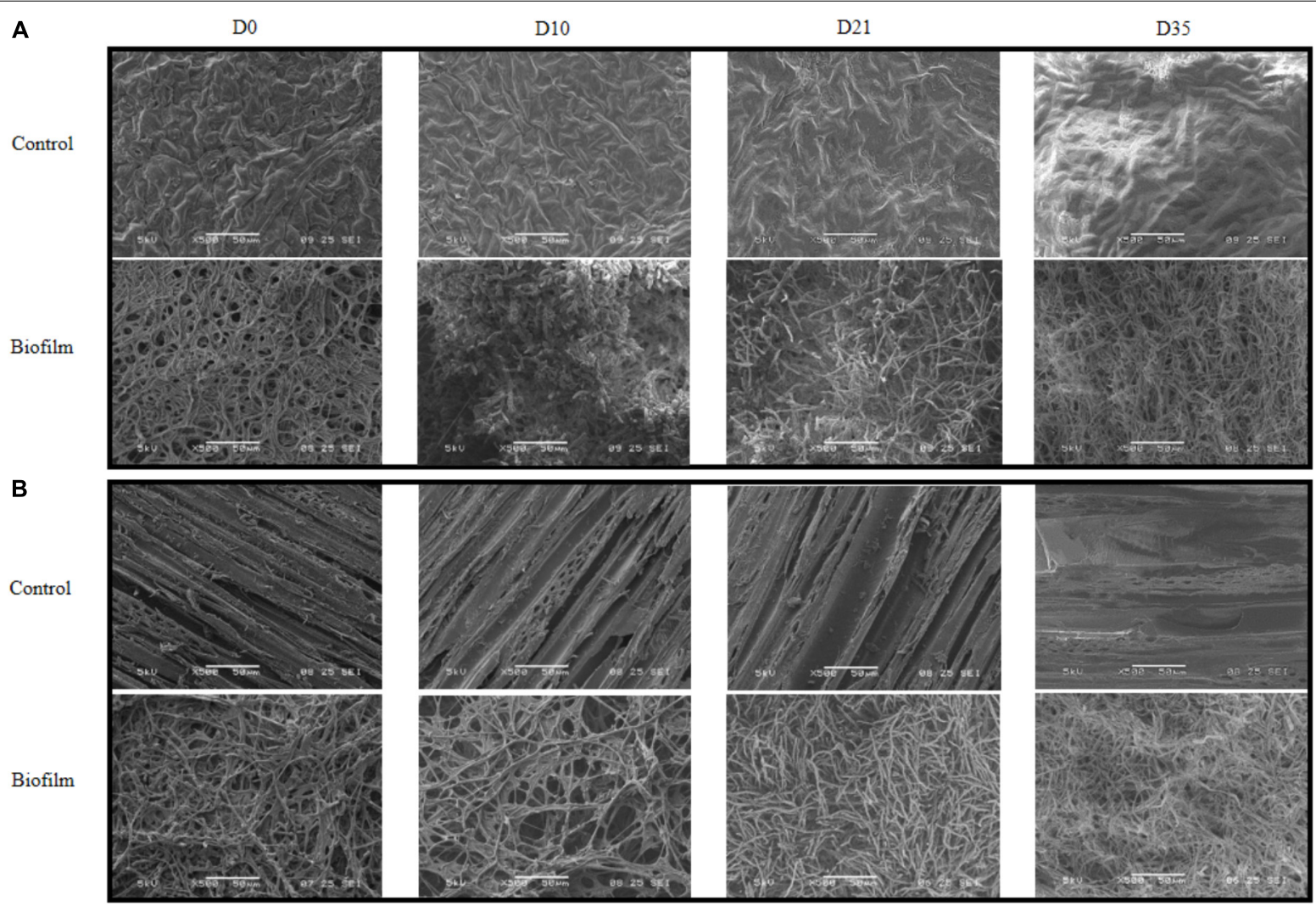

FIGURE 6 | Scanning electron micrographs of leaf (A) or wood (B) surface exposed to $30 \mu \mathrm{M}$ nicosulfuron and colonized (biofilm) or not (control) by P. cucumerina AR1 strain from day 0 (D0; exposure to nicosulfuron) to the end of the experiment (D35). No contamination of the support was observed for control leaf (A) or wood (B) supports throughout the experiment (D0-D35). The support surface is completely covered by P. cucumerina AR1 biofilm before being exposed to nicosulfuron (D0, (A,B)). A fungal development was observed at D10 for leaf (A) and D21 for wood (B) supports with appearance of a more compact and longer mycelium. Scale bars represent $500 \mu \mathrm{m}$. 

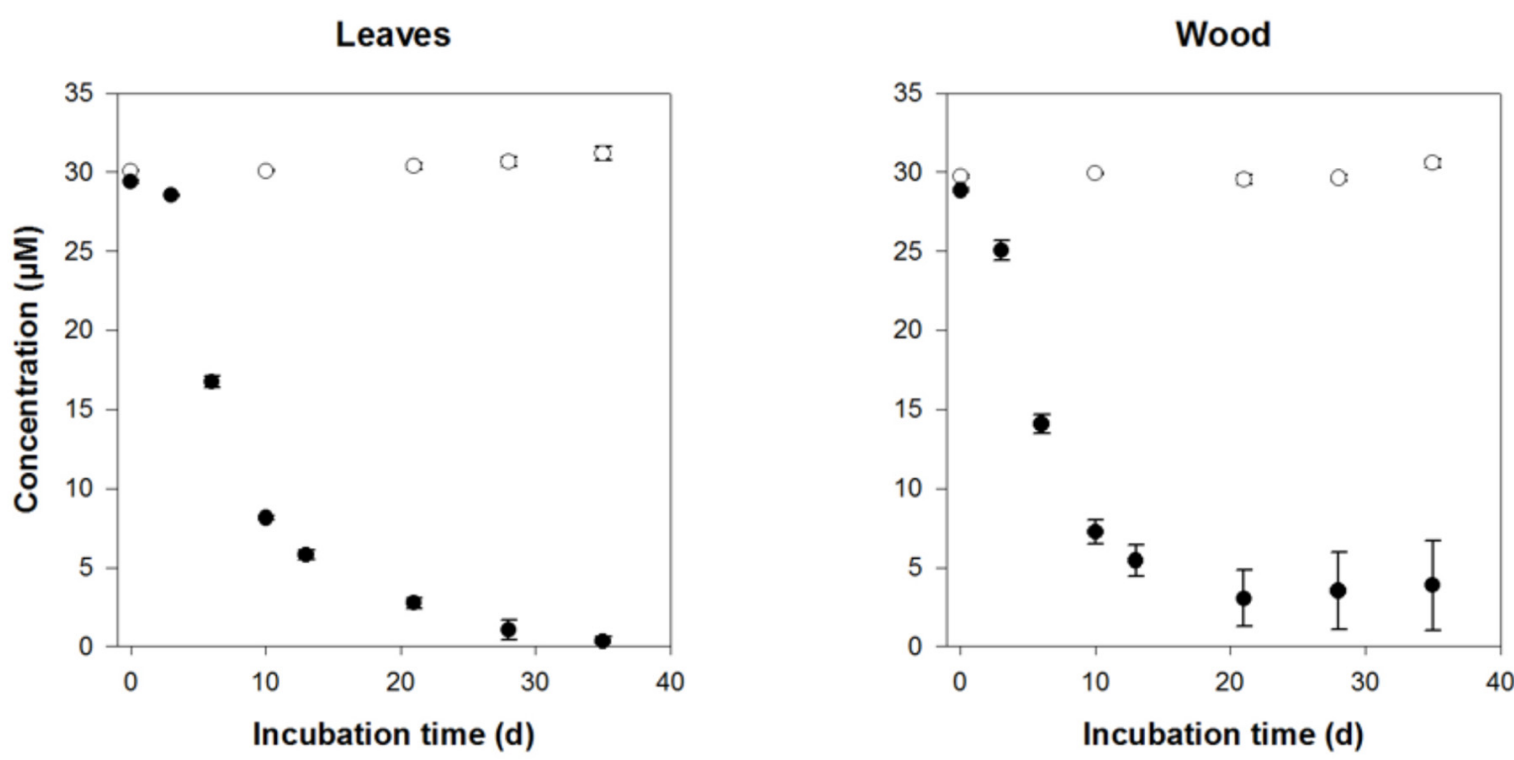

\section{- Abiotic control \\ - Nicosulfuron}

FIGURE 7 | Biodegradation of $30 \mu \mathrm{M}$ nicosulfuron by $P$. cucumerina AR1 biofilms on leaf and wood. The abiotic controls correspond to the substrata non-inoculated by the strain. Values are expressed as the mean \pm standard error (SE), $n=3$.

Our results showed that $P$. cucumerina AR1 can also be used to reduce nicosulfuron contamination since we demonstrated that (i) it was tolerant to nicosulfuron in contrast to what was described for other fungal species (Karpouzas et al., 2014) and (ii) it was able to degrade the nicosulfuron herbicide both in planktonic (Figure 2) and in biofilm conditions with various simple and complex carbon sources (glucose, leaf or wood; Figure 7). Regarding the literature, this is the first time that a leaf-associated fungal strain able to degrade nicosulfuron has been isolated in freshwater, the other ones being isolated from agricultural soil or sludge (Yang et al., 2008; Zhang et al., 2011, 2012; Lu et al., 2012; Song et al., 2013; Zhao et al., 2015a,b, 2018; Wang et al., 2016; Carles et al., 2017a; Feng et al., 2017; Zhou et al., 2017).

As already shown with almost all the isolated nicosulfurondegrading strains, except the Oceanisphaera psychrotolerans LAM-WHM-ZC and Pseudomonas nitroreducens NSA02 strains which are able to degrade nicosulfuron in mineral medium, using nicosulfuron as the carbon source (Zhou et al., 2017; Zhao et al., 2018), the nicosulfuron degradation by $P$. cucumerina AR1 was achieved by a co-metabolism process (Figure 2). Our results showed that the herbicide dissipation was mainly due to biodegradation since the $\mathrm{pH}$ values of the medium of all the cultures remained around neutrality (ranging from 6.1 to 6.7) at the end of the experiment, contrarily to what was observed with Penicillium oxalicum YC-WM1 fungal strain. In this last case, nicosulfuron was degraded by hydrolysis resulting from the acidification of the medium (Feng et al., 2017).
In most cases, the biodegradation rate of a pollutant is improved by the addition of increasing concentrations of the extra carbon source (e. g., Wang et al., 2013; Kirui et al., 2016; Sun et al., 2017) as we observed in our study (Figure 2). However, the specific nicosulfuron biodegradation by the planktonic P. cucumerina AR1 was shown to be greater when the concentration of glucose decreased (Figure 4). This phenomenon has already been described for other pollutants (Ye et al., 2011; Shi et al., 2013; Wu et al., 2016). Indeed, the degradation efficiency increased with increasing concentration of glucose until an optimal concentration. Then, the addition of the carbon source to excess inhibited the degradation. This suggests that the optimal glucose concentration for the maximal degradation efficiency of nicosulfuron by planktonic P. cucumerina AR1 would be around $1 \mathrm{~g} / \mathrm{L}$ under the conditions tested (Figure 4).

Plectosphaerella cucumerina AR1 used the same nicosulfuron degradation pathway irrespective of its lifestyle, planktonic or in biofilms (Figure 2 and Supplementary Figure S1). It produced two major metabolites, ADMP and ASDM, which were obtained by a pathway common to all the strains described until now, consisting in the biotic hydrolytic cleavage of the sulfonylurea bridge (e.g., Zhang et al., 2012; Song et al., 2013; Zhao et al., 2015a, 2018; Wang et al., 2016; Carles et al., 2017a). The minor N3 metabolite was derived from the cleavage of the C-S bond of the sulfonylurea bridge and contraction by elimination of the sulfur dioxide group, as previously observed with some others nicosulfuron-degrading strains (Song 
et al., 2013; Zhao et al., 2015a; Carles et al., 2017a; Zhou et al., 2017). Similarly to what was observed during the nicosulfuron degradation by the bacterial strain Pseudomonas fluorescens SG-1 (Carles et al., 2017a), the hydrolysis of the N3 urea function lead to the production of the N4 metabolite in small amounts when $P$. cucumerina AR1 was grown in benthic conditions (Supplementary Figure S1).

Plectosphaerella cucumerina AR1 strain developed indifferently on both natural substrata studied (alder leaf and hazel wood) (Figure 6). However, the biofilm grew faster on the leaf than on wood. This could be explained by the greater laccase activity rates recorded for the former (Figure 5B). This led to a faster decay of leaves and thus faster nutrient supply for fungal growth comparing to wood substratum which has a more complex molecular arrangement (Golladay and Sinsabaugh, 1991; Gulis et al., 2004). This could also explain the greater laccase activity rates recorded in the leaf substratum (Figure 5B). However, this higher enzyme activity was not correlated with nicosulfuron degradation capacity of $P$. cucumerina AR1, which was similar between leaf and wood biofilms (Table 1). Furthermore, the presence of nicosulfuron did not impact the growth of the fungus since the biofilm development on both substrata was similar to what was observed in the control conditions without herbicide. Similar results were obtained for the planktonic culture conditions for which fungal biomasses were comparable in all experiments, irrespective of the presence of nicosulfuron (Figure 3).

When exposed to nicosulfuron, $P$. cucumerina AR1 biofilms kept the capacity to biodegrade the molecule whatever the substrata tested (Figure 7), thus probably using the decomposition of the natural substrata as nutrients and carbon sources. The present study also shows that nicosulfuron degradation efficiency was greater for P. cucumerina AR1 monospecific biofilms on alder leaves (100\% dissipation after 28 days, the present study) than for plurispecific natural biofilms hosting $P$. cucumerina on the same leaf species (29-66\% dissipation in 40 days, Carles et al., 2017b). The decreased ability of P. cucumerina AR1 to dissipate nicosulfuron could be explained either by a relative low presence of the fungus in the natural leaf-associated microbial communities or by microbial interactions within the biofilm. Overall, this is the first time that a benthic strain was shown to be able to degrade nicosulfuron herbicide, all the degradation experiments conducted until now with isolated bacterial and fungal strains being tested in planktonic conditions (Feng et al., 2017; Yang et al., 2008; Zhang et al., 2011, 2012; Lu et al., 2012; Song et al., 2013; Zhao et al., 2015a,b, 2018; Wang et al., 2016; Carles et al., 2017a; Zhou et al., 2017).

The nicosulfuron degradation obtained for $P$. cucumerina AR1 in biofilm conditions showed statistically similar dissipation rates than those observed in planktonic culture conditions containing $5 \mathrm{~g} / \mathrm{L}$ of glucose (Table 1 ). This suggests that the natural substrata we provided for co-metabolism reactions could not allow $P$. cucumerina AR1 to degrade the nicosulfuron herbicide at the optimal conditions, since we have shown that a lesser carbon concentration equivalent to $1 \mathrm{~g} / \mathrm{L}$ of glucose would be more efficient in planktonic conditions. These results still have to be confirmed in biofilm conditions by testing different leaf and wood substrata varying in their composition, and thus in their capacity of decomposition and releasing nutrients (Bani et al., 2018; Bastias et al., 2018).

In contrast to what was often observed in pollutant exposed microbial communities and/or populations (e.g., da Silva Coelho et al., 2010; Artigas et al., 2017; de Araujo et al., 2017; Singh et al., 2017), the laccase activity decreased in the presence of nicosulfuron, showing a reduction of about $60 \%$ activity, whatever the lifestyle (Figure 5). The obtained results highlight that laccase activity responses to xenobiotic contamination are probably molecule-specific (Baldrian, 2006).

\section{CONCLUSION}

We report here the isolation and characterization of a leaf-associated fungus issued from a river ecosystem, identified as a Plectosphaerella cucumerina strain. This isolated strain was able to biodegrade the nicosulfuron herbicide by a co-metabolic process. The degradation pathway was shown to be common to almost all the already described nicosulfuron-degrading strains, starting with the hydrolytic cleavage of the sulfonylurea bridge. Nicosulfuron exposure impaired the fungal laccase activity. However, $P$. cucumerina AR1 was able to degrade nicosulfuron in planktonic lifestyle using glucose as the carbon source, with an optimal concentration of $1 \mathrm{~g} / \mathrm{L}$. It was also capable of colonizing natural substrata such as alder leaves or hazel wood to form biofilms and to retain its nicosulfuron biodegradation capacity. This suggests that the nutrients and carbon constituting these natural substrata can be used to ensure the co-metabolic reactions and the nicosulfuron dissipation.

Knowing that both leaf and wood surfaces allow the development of extensive biofilms in streams and that fungi are extremely important in their development, the P. cucumerina AR1 strain is considered as a potentially useful candidate for the development of methods aiming to reduce contamination by nicosulfuron in aquatic environments.

\section{AUTHOR CONTRIBUTIONS}

LC and FR set up the experiments, carried out the sampling, and participated to the discussion. CB realized the SEM images. ML carried out the LC-MS analyses. PB-H carried out the HPLC measurements and interpretation. JA isolated the strain and realized the statistical analyses. IB identified the strain. JA and IB designed the experimental work, the cultures of the fungal strain, 
the laccase and biomass measurements, and wrote the first draft of the article. All the authors wrote sections of the manuscript, participated to the reviewing of the article, and approved the submitted version.

\section{FUNDING}

This study was funded by the EcoBioPest project (Agence de l'Eau Loire-Bretagne).

\section{REFERENCES}

Artigas, J., Rossi, F., Gerphagnon, M., and Mallet, C. (2017). Sensitivity of laccase activity to the fungicide tebuconazole in decomposing litter. Sci. Total Environ. 584-585, 1084-1092. doi: 10.1016/j.scitotenv.2017. 01.167

Atkins, S. D., Clark, I. M., Sosnowska, D., Hirsch, P. R., and Kerry, B. R. (2003). Detection and quantification of Plectosphaerella cucumerina, a potential biological control agent of potato cyst nematodes, by using conventional PCR, real-time PCR, selective media, and baiting. Appl. Environ. Microbiol. 69, 4788-4793. doi: 10.1128/AEM.69.8.4788-4793.2003

Azcarate, M. P., Montoya, J. C., and Koskinen, W. C. (2015). Sorption, desorption and leaching potential of sulfonylurea herbicides in Argentinean soils. J. Environ. Sci. Health Part B 50, 229-237. doi: 10.1080/03601234.2015. 999583

Bailey, K., Derby, J.-A., Bourdôt, G., Skipp, B., Cripps, M., Hurrell, G., et al. (2017). Plectosphaerella cucumerina as a bioherbicide for Cirsium arvense: proof of concept. BioControl 62, 693-704. doi: 10.1007/s10526-017-98197

Bailey, K. L., Derby, J., Bourdôt, G. W., Skipp, R. A., and Hurrell, G. A. (2017). Optimising inoculum yield and shelf life of Plectosphaerella cucumerina, a potential bioherbicide for Cirsium arvense. Biocontrol Sci. Technol. 27, 14161434. doi: 10.1080/09583157.2017.1409337

Baldrian, P. (2006). Fungal laccases - Occurrence and properties. FEMS Microbiol. Rev. 30, 215-242. doi: 10.1111/j.1574-4976.2005.00010.x

Bani, A., Pioli, S., Ventura, M., Panzacchi, P., Borruso, L., Tognetti, R., et al. (2018). The role of microbial community in the decomposition of leaf litter and deadwood. Appl. Soil Ecol. 126, 75-84. doi: 10.1016/j.apsoil.2018. 02.017

Bastias, E., Ribot, M., Romaní, A. M., Mora-Gómez, J., Sabater, F., López, P., et al. (2018). Responses of microbially driven leaf litter decomposition to stream nutrients depend on litter quality. Hydrobiologia 806, 333-346. doi: 10.1007/ s10750-017-3372-3

Battaglin, W. A., Furlong, E. T., Burkhardt, M. R., and Peter, C. J. (2000). Occurrence of sulfonylurea, sulfonamide, imidazolinone, and other herbicides in rivers, reservoirs and ground water in the Midwestern United States, 1998. Sci. Total Environ. 248, 123-133. doi: 10.1016/S0048-9697(99) 00536-7

Battaglin, W. A., Rice, K. C., Focazio, M. J., Salmons, S., and Barry, R. X. (2009). The occurrence of glyphosate, atrazine, and other pesticides in vernal pools and adjacent streams in Washington, DC, Maryland, Iowa, and Wyoming, 2005-2006. Environ. Monit. Assess. 155, 281-307. doi: 10.1007/s10661-008$0435-y$

Benzi, M., Robotti, E., and Gianotti, V. (2011). HPLC-DAD-MSn to investigate the photodegradation pathway of nicosulfuron in aqueous solution. Anal. Bioanal. Chem. 399, 1705-1714. doi: 10.1007/s00216-010-4467-0

Berger, B. M., and Wolfe, N. L. (1996). Hydrolysis and biodegradation of sulfonylurea herbicides in aqueous buffers and anaerobic water-sediment systems: assessing fate pathways using molecular descriptors. Environ. Toxicol. Chem. 15:1500. doi: 10.1002/etc.5620150911

Carles, L., Joly, M., Bonnemoy, F., Leremboure, M., Batisson, I., and Besse-Hoggan, P. (2017a). Identification of sulfonylurea biodegradation pathways enabled by a novel nicosulfuron-transforming strain Pseudomonas fluorescens SG-1: toxicity assessment and effect of

\section{ACKNOWLEDGMENTS}

The authors acknowledge Philip Hoggan for English reviewing.

\section{SUPPLEMENTARY MATERIAL}

The Supplementary Material for this article can be found online at: https://www.frontiersin.org/articles/10.3389/fmicb. 2018.03167/full\#supplementary-material

formulation. J. Hazard. Mater. 324, 184-193. doi: 10.1016/j.jhazmat.2016. 10.048

Carles, L., Rossi, F., Joly, M., Besse-Hoggan, P., Batisson, I., and Artigas, J. (2017b). Biotransformation of herbicides by aquatic microbial communities associated to submerged leaves. Environ. Sci. Pollut. Res. 24, 3664-3674. doi: 10.1007/ s11356-016-8035-9

Carlucci, A., Raimondo, M. L., Santos, J., and Phillips, A. J. L. (2012). Plectosphaerella species associated with root and collar rots of horticultural crops in southern Italy. Persoonia - Mol. Phylogeny Evol. Fungi 28, 34-48. doi: $10.3767 / 003158512 X 638251$

Cessna, A. J., Donald, D. B., Bailey, J., and Waiser, M. (2015). Persistence of the sulfonylurea herbicides sulfosulfuron, rimsulfuron, and nicosulfuron in farm dugouts (Ponds). J. Environ. Qual. 44:1948. doi: 10.2134/jeq2014. 11.0503

da Silva Coelho, J., de Oliveira, A. L., Marques, de Souza, C. G., and Bracht, A. (2010). Effect of the herbicides bentazon and diuron on the production of ligninolytic enzymes by Ganoderma lucidum. Int. Biodeterior. Biodegrad. 64, 156-161. doi: 10.1016/j.ibiod.2009.12.006

Dandurand, L.-M., and Knudsen, G. R. (2016). Effect of the trap crop Solanum sisymbriifolium and two biocontrol fungi on reproduction of the potato cyst nematode, Globodera pallida: trap crop and biocontrol agent effects on Globodera pallida. Ann. Appl. Biol. 169, 180-189. doi: 10.1111/aab. 12295

de Araujo, C. A. V., Maciel, G. M., Rodrigues, E. A., Silva, L. L., Oliveira, R. F., Brugnari, T., et al. (2017). Simultaneous removal of the antimicrobial activity and toxicity of sulfamethoxazole and trimethoprim by white rot fungi. Water. Air. Soil Pollut. 228:341. doi: 10.1007/s11270-0173525-z

de Lafontaine, Y., Beauvais, C., Cessna, A. J., Gagnon, P., Hudon, C., and Poissant, L. (2014). Sulfonylurea herbicides in an agricultural catchment basin and its adjacent wetland in the St. Lawrence River basin. Sci. Total Environ. 47, 1-10. doi: 10.1016/j.scitotenv.2014. 01.094

EFSA (2007). Conclusion regarding the peer review of the pesticide risk assessment of the active substance nicosulfuron. EFSA Sci. Rep. 120, 1-91. doi: 10.2903/j. efsa.2008.120r

Feng, W., Wei, Z., Song, J., Qin, Q., Yu, K., Li, G., et al. (2017). Hydrolysis of nicosulfuron under acidic environment caused by oxalate secretion of a novel Penicillium oxalicum strain YC-WM1. Sci. Rep. 7:647. doi: 10.1038/s41598-01700228-2

Gao, J., Zhang, Y. Y., Zhao, X. J., Wang, K., and Zhao, J. (2016). First report of potato wilt caused by Plectosphaerella cucumerina in Inner mongolia, China. Plant Dis. 100:2523. doi: 10.1094/PDIS-01-16-0028-PDN

Golladay, S. W., and Sinsabaugh, R. L. (1991). Biofilm development on leaf and wood surfaces in a boreal river. Freshw. Biol. 25, 437-450. doi: 10.1111/j.13652427.1991.tb01387.x

Gonzalez, J., and Ukrainczyk, L. (1999). Transport of nicosulfuron in soil columns. J. Environ. Qual. 28:101. doi: 10.2134/jeq1999.00472425002800010011x

Gonzalez, J. M., and Ukrainczyk, L. (1996). Adsorption and desorption of nicosulfuron in soils. J. Environ. Qual. 25:1186. doi: 10.2134/jeq1996. $00472425002500060003 x$

Gulis, V., Rosemond, A. D., Suberkropp, K., Weyers, H. S., and Benstead, J. P. (2004). Effects of nutrient enrichment on the decomposition of wood and 
associated microbial activity in streams. Freshw. Biol. 49, 1437-1447. doi: 10. 1111/j.1365-2427.2004.01281.x

Jacobs, H., Gray, S. N., and Crump, D. H. (2003). Interactions between nematophagous fungi and consequences for their potential as biological agents for the control of potato cyst nematodes. Mycol. Res. 107, 47-56. doi: 10.1017/S095375620200 7098

Johannes, C., and Majcherczyk, A. (2000). Laccase activity tests and laccase inhibitors. J. Biotechnol. 78, 193-199. doi: 10.1016/S0168-1656(00)00208-X

Karpouzas, D. G., Papadopoulou, E., Ipsilantis, I., Friedel, I., Petric, I., UdikovicKolic, N., et al. (2014). Effects of nicosulfuron on the abundance and diversity of arbuscular mycorrhizal fungi used as indicators of pesticide soil microbial toxicity. Ecol. Indic. 39, 44-53. doi: 10.1016/j.ecolind.2013. 12.004

Kirui, W. K., Wu, S., Kizito, S., Carvalho, P. N., and Dong, R. (2016). Pathways of nitrobenzene degradation in horizontal subsurface flow constructed wetlands: effect of intermittent aeration and glucose addition. J. Environ. Manage. 166, 38-44. doi: 10.1016/j.jenvman.2015.10.001

Kooliyottil, R., Dandurand, L.-M., and Knudsen, G. R. (2017). Prospecting fungal parasites of the potato cyst nematode Globodera pallida using a rapid screening technique. J. Basic Microbiol. 57, 386-392. doi: 10.1002/jobm.20160 0683

Krauss, G.-J., Solé, M., Krauss, G., Schlosser, D., Wesenberg, D., and Bärlocher, F. (2011). Fungi in freshwaters: ecology, physiology and biochemical potential. FEMS Microbiol. Rev. 35, 620-651. doi: 10.1111/j.1574-6976.2011.0 0266.x

Li, P.-L., Chai, A.-L., Shi, Y.-X., Xie, X.-W., and Li, B.-J. (2017). First report of root rot caused by Plectosphaerella cucumerina on cabbage in China. Mycobiology 45, 110-113. doi: 10.5941/MYCO.2017.45.2.110

López-Legentil, S., Erwin, P. M., Turon, M., and Yarden, O. (2015). Diversity of fungi isolated from three temperate ascidians. Symbiosis 66, 99-106. doi: 10.1007/s13199-015-0339-X

Lu, X. H., Kang, Z. H., Tao, B., Wang, Y. N., Dong, J. G., and Zhang, J. L. (2012). Degradation of nicosulfuron by Bacillus subtilis YB1 and Aspergillus niger YF1. Appl. Biochem. Microbiol. 48, 460-466. doi: 10.1134/S00036838120 50079

Moschet, C., Wittmer, I., Simovic, J., Junghans, M., Piazzoli, A., Singer, H., et al. (2014). How a complete pesticide screening changes the assessment of surface water quality. Environ. Sci. Technol. 48, 5423-5432. doi: 10.1021/es50 $0371 \mathrm{t}$

O'Donnell, K., and Gray, L. (1995). Phylogenetic relationships of the soybean sudden death syndrome pathogen Fusarium solani f. sp. phaseoli inferred from rDNA sequence data and pcr primers for its identification. Mol. Plant. Microbe Interact. 8:709. doi: 10.1094/MPMI-8-0709

Oliveira, R. S., Koskinen, W. C., and Ferreira, F. A. (2001). Sorption and leaching potential of herbicides on Brazilian soils. Weed Res. 41, 97-110. doi: 10.1046/j. 1365-3180.2001.00219.x

Petric, I., Karpouzas, D. G., Bru, D., Udikovic-Kolic, N., Kandeler, E., Djuric, S., et al. (2016). Nicosulfuron application in agricultural soils drives the selection towards NS-tolerant microorganisms harboring various levels of sensitivity to nicosulfuron. Environ. Sci. Pollut. Res. 23, 4320-4333. doi: 10.1007/s11356-0155645-6

Pfeiffer, M. (2010). Groundwater Ubiquity Score (GUS). Corvallis, OR: National Pesticide Information Center.

Regitano, J. B., and Koskinen, W. C. (2008). Characterization of nicosulfuron availability in aged soils. J. Agric. Food Chem. 56, 5801-5805. doi: 10.1021/ jf800753p

Santelli, C. M., Pfister, D. H., Lazarus, D., Sun, L., Burgos, W. D., and Hansel, C. M. (2010). Promotion of $\mathrm{Mn}(\mathrm{II})$ oxidation and remediation of coal mine drainage in passive treatment systems by diverse fungal and bacterial communities. Appl. Environ. Microbiol. 76, 4871-4875.doi: 10.1128/AEM. 03029-09

Santelli, C. M., Webb, S. M., Dohnalkova, A. C., and Hansel, C. M. (2011). Diversity of $\mathrm{Mn}$ oxides produced by $\mathrm{Mn}(\mathrm{II})$-oxidizing fungi. Geochim. Cosmochim. Acta 75, 2762-2776. doi: 10.1016/j.gca.2011.02.022

Sarmah, A. K., and Sabadie, J. (2002). Hydrolysis of sulfonylurea herbicides in soils and aqueous solutions: a review. J. Agric. Food Chem. 50, 6253-6265. doi: $10.1021 /$ jf025575p
Schloss, J. V. (1990). Acetolactate synthase, mechanism of action and its herbicide binding site. Pestic. Sci. 29, 283-292. doi: 10.1002/ps.2780290305

Shi, G., Yin, H., Ye, J., Peng, H., Li, J., and Luo, C. (2013). Aerobic biotransformation of decabromodiphenyl ether (PBDE-209) by Pseudomonas aeruginosa. Chemosphere 93, 1487-1493. doi: 10.1016/j.chemosphere.2013.07. 044

Singh, S. K., Khajuria, R., and Kaur, L. (2017). Biodegradation of ciprofloxacin by white rot fungus Pleurotus ostreatus. 3 Biotech 7:69. doi: 10.1007/s13205-0170684-y

Song, J., Gu, J., Zhai, Y., Wu, W., Wang, H., Ruan, Z., et al. (2013). Biodegradation of nicosulfuron by a Talaromyces flavus LZM1. Bioresour. Technol. 140, 243248. doi: 10.1016/j.biortech.2013.02.086

Sun, Z., Li, J., Zhang, J., Wang, J., Wang, X., and Hu, X. (2017). Effect of glucose as co-metabolism substrate on the biodegradation of dichlorophenols. FRESENIUS Environ. Bull. 26, 6017-6027.

Trigo, C., Spokas, K. A., Cox, L., and Koskinen, W. C. (2014). Influence of soil biochar aging on sorption of the herbicides MCPA, nicosulfuron, terbuthylazine, indaziflam, and fluoroethyldiaminotriazine. J. Agric. Food Chem. 62, 10855-10860. doi: 10.1021/jf5034398

Usami, T., and Katagiri, H. (2017). Pathogenicity of Plectosphaerella species on lettuce and susceptibility of lettuce cultivars. J. Gen. Plant Pathol. 83, 366-372. doi: 10.1007/s10327-017-0736-5

Velmurugan, N., Kalpana, D., Han, J. H., Cha, H. J., and Soo Lee, Y. (2011). A novel low temperature chitinase from the marine fungus Plectosphaerella sp. strain MF-1. Bot. Mar. 54, 75-81. doi: 10.1515/bot.2010.068

Wang, G., Chen, X., Yue, W., Zhang, H., Li, F., and Xiong, M. (2013). Microbial degradation of acetamiprid by Ochrobactrum sp. D-12 isolated from contaminated soil. PLoS One 8:e82603. doi: 10.1371/journal.pone.008 2603

Wang, G., Li, Q., and Zhu, P. (2008). Phylogenetic diversity of culturable fungi associated with the Hawaiian Sponges Suberites zeteki and Gelliodes fibrosa. Antonie Van Leeuwenhoek 93, 163-174. doi: 10.1007/s10482-007-9190-2

Wang, L., Zhang, X., and Li, Y. (2016). Degradation of nicosulfuron by a novel isolated bacterial strain Klebsiella sp. Y1: condition optimization, kinetics and degradation pathway. Water Sci. Technol. 73, 2896-2903. doi: 10.2166/wst.2016. 140

White, T. J., Bruns, T., Lee, S., Taylor, J. W., Innis, M. A., Gelfand, D. H., et al. (1990). Amplification and direct sequencing of fungal ribosomal RNA genes for phylogenetics. PCR Protoc. Guide Methods Appl. 18, 315-322. doi: 10.1016/ B978-0-12-372180-8.50042-1

Wu, H., Shen, J., Wu, R., Sun, X., Li, J., Han, W., et al. (2016). Biodegradation mechanism of 1H-1,2,4-triazole by a newly isolated strain Shinella sp. NJUST26. Sci. Rep. 6:29675. doi: 10.1038/srep29675

Xu, D. S., Zhang, Y. Y., Zhao, J. X., and Zhao, J. (2016). First Report of broomrape wilt caused by Plectosphaerella cucumerina in inner Mongolia, China. Plant Dis. 100, 2538-2538. doi: 10.1094/PDIS-03-16-0296-PDN

Yan, L. Y., Ying, Q. S., Wang, Y. E., Zhang, H. F., and Wang, Y. H. (2016). First report of root and collar rot caused by Plectosphaerella cucumerina on bottle gourd in China. Plant Dis. 100, 1505-1505. doi: 10.1094/PDIS-11-15-1305PDN

Yang, Y., Tao, B., Zhang, W., and Zhang, J. (2008). Isolation and screening of microorganisms capable of degrading nicosulfuron in water. Front. Agric. China 2:224-228. doi: 10.1007/s11703-008-0033-3

Ye, J.-S., Yin, H., Qiang, J., Peng, H., Qin, H.-M., Zhang, N., et al. (2011). Biodegradation of anthracene by Aspergillus fumigatus. J. Hazard. Mater. 185, 174-181. doi: 10.1016/j.jhazmat.2010.09.015

Zhang, G., Zhang, S., Liu, Y., and Tan, Z. (2011). Isolation and identification of a nicosulfuron-degrading strain J5-2 and its degradation characteristics. Environ. Pollut. Control 5:3.

Zhang, H., Mu, W., Hou, Z., Wu, X., Zhao, W., Zhang, X., et al. (2012). Biodegradation of nicosulfuron by the bacterium Serratia marcescens N80. J. Environ. Sci. Health Part B 47, 153-160. doi: 10.1080/03601234.2012.632249

Zhang, Y. Y., Li, M., Liang, Y., Zhou, H. Y., and Zhao, J. (2015). First report of sunflower wilt caused by Plectosphaerella cucumerina in China. Plant Dis. 99, 1646-1646. doi: 10.1094/PDIS-02-15-0135-PDN

Zhao, H., Zhu, J., Liu, S., and Zhou, X. (2018). Kinetics study of nicosulfuron degradation by a Pseudomonas nitroreducens strain NSA02. Biodegradation 29, 271-283. doi: 10.1007/s10532-018-9828-y 
Zhao, W., Wang, C., Xu, L., Zhao, C., Liang, H., and Qiu, L. (2015a). Biodegradation of nicosulfuron by a novel Alcaligenes faecalis strain ZWS11. J. Environ. Sci. 35, 151-162. doi: 10.1016/j.jes.2015.03.022

Zhao, W., Xu, L., Li, D., Li, X., Wang, C., Zheng, M., et al. (2015b). Biodegradation of thifensulfuron-methyl by Ochrobactrum sp. in liquid medium and soil. Biotechnol. Lett. 37, 1385-1392. doi: 10.1007/s10529-0151807-3

Zhou, S., Song, J., Dong, W., Mu, Y., Zhang, Q., Fan, Z., et al. (2017). Nicosulfuron biodegradation by a novel cold-adapted strain Oceanisphaera psychrotolerans LAM-WHM-ZC. J. Agric. Food Chem. 65, 10243-10249. doi: 10.1021/acs.jafc. $7 \mathrm{~b} 04022$
Conflict of Interest Statement: The authors declare that the research was conducted in the absence of any commercial or financial relationships that could be construed as a potential conflict of interest.

Copyright (c) 2018 Carles, Rossi, Besse-Hoggan, Blavignac, Leremboure, Artigas and Batisson. This is an open-access article distributed under the terms of the Creative Commons Attribution License (CC BY). The use, distribution or reproduction in other forums is permitted, provided the original author(s) and the copyright owner(s) are credited and that the original publication in this journal is cited, in accordance with accepted academic practice. No use, distribution or reproduction is permitted which does not comply with these terms. 